\title{
Morphological and histological structure characteristics of the gastrointestinal tract in Sinogastromyzon szechuanensis
}

\author{
Lin Song, Jiangu Wu, Xiaojiang Chen*, Xiaolong Huang, Yan Shao \\ Jiangsu Agri-animal Husbandry Vocational College. Taizhou, China \\ *Corresponding Author’s e-mail: cq_cxj@126.com
}

Keywords: Sinogastromyzon szechuanensis; morphology; histology.

\begin{abstract}
: in order to understand the morphological structure characteristics of the stomach and intestinal tract of Sinogastromyzon szechuanensis, we observed and studied the morphological and histological structure characteristics of the gastrointestinal tract of Sinogastromyzon szechuanensis by means of anatomy, tissue section and light microscopy. The results show that the stomach of Sinogastromyzon szechuanensis is U-shaped, and the intestinal tract is composed of three parts: foregut, midgut and hindgut. The coefficient of intestinal tract is $1.42 \pm 0.20$. The stomach and intestine consist of mucosa, submucosa, muscle layer and serosa. The gastric glands in the stomach are very developed, the wrinkles in the internal surface of intestine are very developed, the mucosal epithelium is a single-layer columnar epithelium, and on the free surface of it, there is the striated border formed by the dense arrangement of microvilli; the goblet cells are distributed among the epithelial cells, and the number of goblet cells gradually increases from the foregut to the hindgut. The number of wrinkles of intestinal mucosa gradually decreases from the foregut to the hindgut, and the height also decreases, while the thickness of muscle layer gradually increases. The results show that the morphological and histological structure characteristics of the stomach and intestinal tract of Sinogastromyzon szechuanensis are adapted to its omnivorous and partial carnivorous nature.
\end{abstract}

Sinogastromyzon szechuanensis is a kind fish belonging to Balitoridae, Sinogastromyzon. Because of its unique body shape and unique movement mode, it is an ornamental fish with unique style and development value. But they have high environmental requirements and they need clean water and high oxygen environment, so it is difficult to raise them. At present, overfishing and environmental damage have led to a sharp decline in the population resources. Now, they are only found in the middle and upper reaches of the Yangtze River, and have been listed as key protected fish by Sichuan, Yunnan, Guizhou and Chongqing, and there are documents such as the Chongqing Municipal Government Document ([1999] No.65 issued by Chongqing Municipal Government) ${ }^{[1-3]}$.

The stomach and intestinal tract are important digestive and absorption organs for fish to maintain life activities, which have a very important impact on fish growth, development and reproduction. Therefore, studying and discussing the histology and morphology of the stomach and intestines of fish is helpful for us to understand and understand the physiological mechanism of feeding, digestion and absorption of fish ${ }^{[4]}$. There are few published literatures about Sinogastromyzon szechuanensis, and they mainly focus on resource investigation, reproductive activity, early development, mitochondrial genome and phylogeny analysis ${ }^{[5-14]}$. We have not seen the morphological and histological studies on the stomach and intestinal tract of Sinogastromyzon szechuanensis. In this study, the morphology and tissue structure of stomach and intestinal tract of Sinogastromyzon szechuanensis were observed and analyzed by technology of paraffin section and light microscopy, so as to provide histological data for the physiological functions of eating, digestion and absorption of Sinogastromyzon szechuanensis and provide reference for the artificial culture of Sinogastromyzon szechuanensis. 


\section{Materials and methods}

\subsection{The tested fish}

The tested fish were collected from Nei-jiang City, Tuo-jiang River system, Sichuan Province, N $29^{\circ} 36^{\prime} 41.93^{\prime \prime}$, E $105^{\circ} 01^{\prime} 47.67 "$. After one month's indoor aquaculture and domestication with circulating water, we selected 10 healthy Sinogastromyzon szechuanensis with uniform specifications, and there was no injury on the body surface. The weight of the sample was (2.35 \pm $0.24) \mathrm{g}$, and the body length was $(5 \pm 0.14) \mathrm{cm}$.

\subsection{Sample collection and preparation}

The samples were taken half an hour after the fish was fed. We quickly fished the fish, weighed the weight of the fish and measured its length. Execute it, dissect it, open the abdominal cavity, observe the position of each organ, and then dissect it and take out the digestive tract, measure the length of the intestine, and calculate the intestine body length index.

Intestine body length index $=\mathrm{GL} / \mathrm{BL}$

Where GL represents the length of intestine and BL represents the length of body.

Cut about $0.5 \mathrm{~cm}$ tissue blocks from the central part of the stomach, foregut, midgut and hindgut of Sinogastromyzon szechuanensis respectively, and then rapidly fix them in Bouin's solution. When preparing the sample, take it out, wash it with water according to the routine preparation procedure for tissue section, then dehydrate it with 30\%, 50\%, 70\%, 80\%, 90\%, 95\% and 100\% ethanol gradients, put it in xylene to make it transparent, and finally embed it in paraffin with low melting point. Then, use YD-202 microtome to section it transversely, and the thickness is $5 \mu \mathrm{m}$. Then, place the section on a clean glass slide, and stain it with HE staining, and seal the section with neutral balsam. Observe and film it with OLYMPUS DP72 optical microscope. The evaluation parameters of intestinal morphology include: the number of mucosa wrinkles on the cross section of digestive tract; the height of mucosa wrinkles; the width of lamina propria in wrinkles; the thickness of submucosa; the degree of infiltration of basophils into the lamina propria and submucosa; the presence and the number of vacuoles on the nucleus; the thickness of muscle layer.

\subsection{Data statistics}

The test results are expressed as "average value \pm standard deviation”. For all statistical analysis, we used SPSS 17.0 software. After the data was analyzed by ANOVA, we used Turkey's multiple comparisons to analyze the significance of the differences between tissues, and the significance level is 0.05 .

\section{Test result}

\subsection{Morphological structure of stomach and intestinal tract of Sinogastromyzon szechuanensis}

From the point of view of morphology (Fig. 1), the stomach and intestinal tract of Sinogastromyzon szechuanensis hover in the abdominal cavity, which can be divided into four parts: stomach, foregut, midgut and hindgut. The stomach is dilated and saclike, and it is in the shape of " $U$ ", which is divided into the cardiac part, the blind sac and the pyloric part. The length of the intestine is $(7.08 \pm 0.90) \mathrm{cm}$, and the intestine body length index is $1.42 \pm 0.20$. The whole length of the intestinal tract is longer than that of the body, and the shape of the intestine is not straight but curved. The part from the connection with the stomach to the first turning point is the foregut, the part from the first turning point to the last turning point is the midgut, and the part from the last turning point to the anus is the hindgut. From the foregut to the midgut, the diameter becomes smaller and the dividing point is obvious, but there is little difference between the diameters of midgut and hindgut 


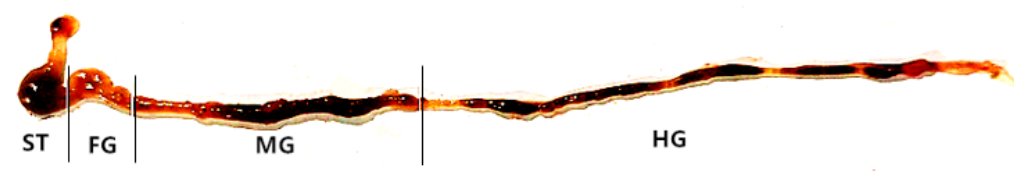

Fig.1 Anatomical form of stomach and intestinal tract of Sinogastromyzon szechuanensis ST: stomach; FG: foregut; MG: midgut; HG: hindgut

\subsection{Tissue structure of stomach and intestinal tract of Sinogastromyzon szechuanensis}

\subsubsection{Stomach}

The tissue structure of the stomach can be divided into mucosa, submucosa, muscle layer and serosa (Chart I-1). The mucosa epithelium of the stomach is composed of a single layer of columnar cells, which are arranged orderly and closely, with goblet cells distributed among them; the nucleus is long oval and located at the cell base, with deep staining; free lymphocytes can also be seen in the epithelial layer. The wrinkles of mucosa are dense, but there is no branching phenomenon and the height is $(11.65 \pm 2.95) \mu \mathrm{m}$. The epithelium is sunken downward, forming a gastric pit (Chart I-1). Under the epithelial cells, there is the lamina propria, and the lamina propria of the cardiac stomach contains the gastric gland tissue. Most of them are composed of several to more than ten layers of round or oval acinus, which opens at the gastric pit, and they are arranged in a single layer and are long and narrow (Chart I-1); the gastric glands in the blind sac are arranged in multiple layers, and most of them are round, and the bottom reaches the submucosa (Chart I-2). During HE staining, the HE staining of gastric gland cells was deep, and there was only one kind of low columnar cells that formed the gastric gland. The connective tissue between the gastric glands can reach the columnar cells of the mucosa. The gastric gland tissue in the pylorus is undeveloped, and the gastric gland tissue near the intestine disappears. No mucosa muscle was observed in the stomach of Sinogastromyzon szechuanensis. The connective tissue of lamina propria and the connective tissue submucosa are continuous, and there is no obvious demarcation line, and there are a large number of dispersedly-distributed circular smooth muscle fibers. There are large blood vessels, lymphatics and nerves in the submucosa. The muscle layer is developed, and it is composed of smooth muscle. The serosa is thin.
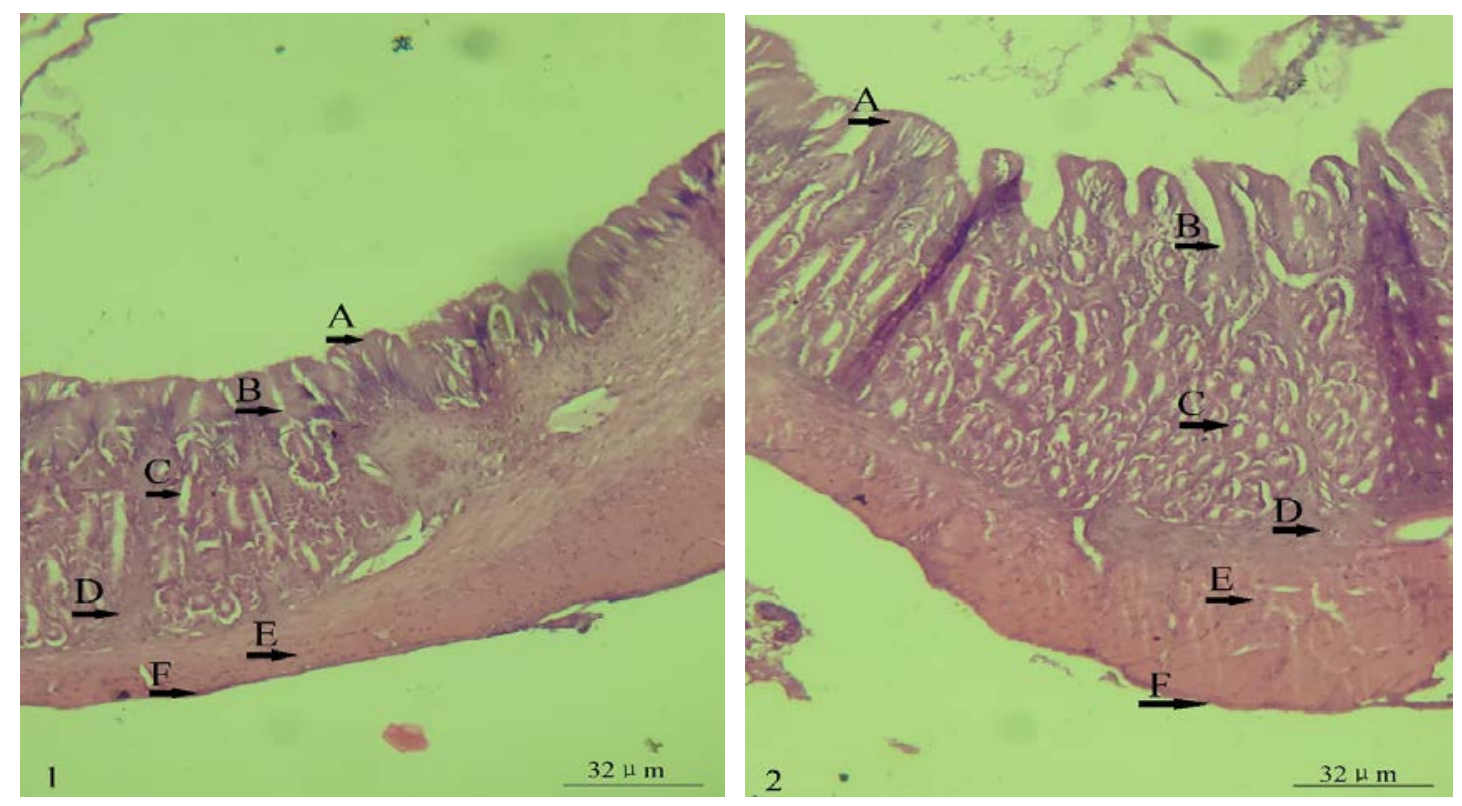


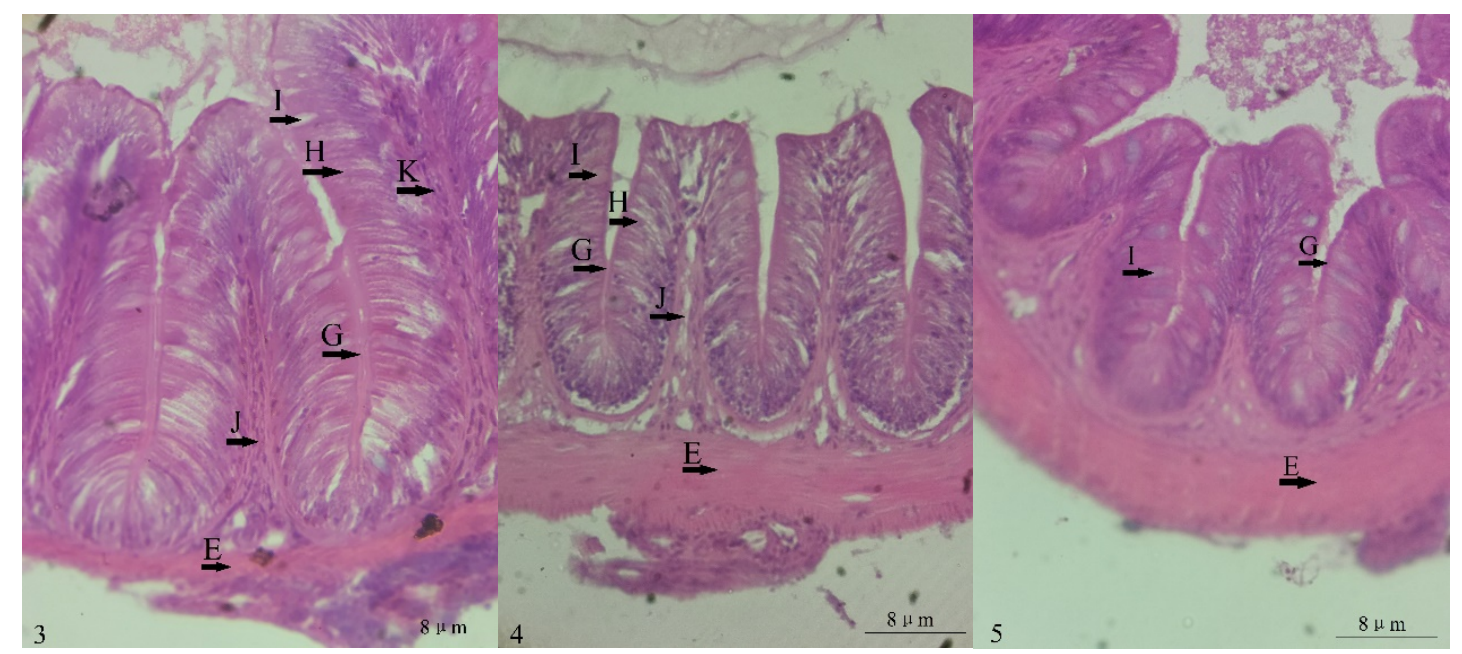

Chart I

1: Cardiac stomach; 2: Blind sac; 3: Foregut; 4: Midgut; 5: Hindgut

Note: “ $\uparrow$ " refers to the A mucosa layer; B gastric pit; C gastric gland; D submucosa; E muscle layer;

F serosa; G brush border; H absorptive cell; I goblet cell; J lamina propria

\subsubsection{Intestinal tract}

Under the light microscope, the tissue structure of each section of intestinal wall of Pelteobagrus fulvidraco is basically the same. The walls of foregut, midgut and hindgut are composed of four layers: mucosa, submucosa, muscle layer and serosa (Chart I-3). The mucosa is composed of epithelium and lamina propria. There is no muscularis mucosa, which makes the distinction between lamina propria and submucosa not obvious. The mucosa epithelium is mainly composed of high columnar absorptive cells and goblet cells, mainly absorptive cells. The nucleus is oval and it is close to the cell base. The staining of the free surface of the cells is deep, and it is a regular band structure, and it is a striated border, and this phenomenon is obvious on each segment of the intestine. The number of goblet cells is relatively small, scattered among the absorbing cells, and the HE staining is vacuolar. Under the epithelium, the lamina propria is composed of dense connective tissue. No intestinal gland was observed in any segment of the intestine. The submucosa is undeveloped, and the muscle layer is divided into two layers: the inner circular muscle and the outer longitudinal muscle. The circular muscle layer is relatively more developed. The serosa is composed of a thin layer of connective tissue and its surrounding mesothelium (Chart I-3,4,5).

The difference of the histological structure of the foregut, midgut and hindgut of Sinogastromyzon szechuanensis is mainly seen in the mucosa (Table 1). The intestinal mucosa protrudes to the intestinal cavity and forms a wrinkle wall, and the wrinkle walls of the foregut are high and many. The average wrinkle height of mucosa is $8.59 \mu \mathrm{m}$; the number of wrinkles of midgut mucosa is generally 16 , and the height is lower than that of foregut, which is $6.63 \mu \mathrm{m}$ averagely; the top of hindgut wrinkle is sometimes blunt, and the wrinkle number of mucosa is significantly reduced, which is generally 12 , which is $7.85 \mu \mathrm{m}$ averagely, which is slightly higher than that of midgut, but still lower than that of foregut. The thicknesses of muscle layers are about $0.27 \mu \mathrm{m}, 0.36 \mu \mathrm{m}$ and $0.41 \mu \mathrm{m}$ respectively. In the foregut and midgut, we can observe more goblet cells. In the hindgut, goblet cells are densely distributed. The thickness of the submucosa in the foregut, midgut and hindgut are about $1.38 \mu \mathrm{m}, 1.38 \mu \mathrm{m}$ and $1.33 \mu \mathrm{m}$ respectively, and the difference is not significant. 
Table 1. Measurement parameters of tissue structure of stomach and intestinal tract of Sinogastromyzon szechuanensis

\begin{tabular}{cccccc}
\hline Tissue & $\begin{array}{c}\text { Diameter of the } \\
\text { intestinal } \\
\text { circle } / \mu \mathrm{m}\end{array}$ & $\begin{array}{c}\text { Number of } \\
\text { folds in } \\
\text { mucosa }\end{array}$ & $\begin{array}{c}\text { Height of folds } \\
\text { in mucosa/ } / \mu \mathrm{m}\end{array}$ & $\begin{array}{c}\text { Height of } \\
\text { submucosa/ } \mu \mathrm{m}\end{array}$ & $\begin{array}{c}\text { Thickness of } \\
\text { muscle } \\
\text { layer/ } \mu \mathrm{m}\end{array}$ \\
\hline Stomach & & $16.00 \pm 1.26^{\mathrm{a}}$ & $11.65 \pm 2.95^{\mathrm{a}}$ & $7.45 \pm 1.71^{\mathrm{a}}$ & $2.69 \pm 0.98^{\mathrm{a}}$ \\
Foregut & $66.50 \pm 8.17$ & $16.80 \pm 1.48^{\mathrm{a}}$ & $8.59 \pm 2.76^{\mathrm{ab}}$ & $1.38 \pm 0.13^{\mathrm{b}}$ & $0.27 \pm 0.04^{\mathrm{b}}$ \\
Midgut & $49.17 \pm 5.75$ & $16.33 \pm 2.33^{\mathrm{a}}$ & $6.63 \pm 1.69^{\mathrm{b}}$ & $1.38 \pm 0.37^{\mathrm{b}}$ & $0.36 \pm 0.09^{\mathrm{b}}$ \\
Hindgut & $49.50 \pm 3.39$ & $12.83 \pm 1.72^{\mathrm{b}}$ & $7.85 \pm 1.65^{\mathrm{ab}}$ & $1.33 \pm 0.33^{\mathrm{b}}$ & $0.41 \pm 0.17^{\mathrm{b}}$ \\
\hline
\end{tabular}

Note: That the shoulder mark of the data in the same column does not contain the same letter indicates that the difference is significant $(\mathrm{P}<0.05)$.

\section{Discussion}

\subsection{Adaptability between the morphological characteristics of stomach and intestinal tract and the eating habits}

The intestinal tract coefficient of fish is closely related to its feeding habits ${ }^{[15]}$. Generally, the intestine of phytophagous fish is more complex and the relative gut length is larger. In general, the intestines of carnivorous fish are straight, no bending or individual bending, and the relative gut length is the smallest ${ }^{[16]}$, while that of omnivorous fish is generally between the two above. The intestine length of fish will change with the change of feeding conditions. At the same time, during the development of individual fish, the length of intestine will change significantly. Moreover, the intestine length of omnivorous fish also depends on the proportion change of the components of the food they eat ${ }^{[17]}$. The specific relative gut length of $S$. nukiangensis and ptychobarbus kaznakovi are $2.96 \pm 0.92$ and $1.46 \pm 0.39$ respectively, and that of schizophylgopsis thermalis is $3.41 \pm 1.26$, the former two are omnivorous and partially carnivorous, the latter is omnivorous and partially phytophagous ${ }^{[18]}$. The intestinal coefficient of Sinogastromyzon szechuanensis is $1.42 \pm 0.20$, and although they are all omnivorous fish, the specific food preferences of different fish are different, and the feeding habits are different from Schizopygopsis thermalis, but similar to S. nukiangensis, they are omnivorous and carnivorous.

\subsection{Adaptability between the tissue structure characteristics of stomach and intestinal tract and the eating habits}

The developed "U" shaped stomach of Sinogastromyzon szechuanensis can hold a lot of food and prolong the digestion time; the mucosa of the stomach forms high and bulging mucosa wrinkles, indicating that the stomach has a very large range of expansion and contraction, which is very beneficial to increase the volume of stomach, the surface area of mucosa and the digestion of food. Under the epithelial cells, there is gastric gland tissue, which is the same as it that $S$. canaliculatus, $R$. sarba and L. crocea ${ }^{[19-21]}$ and other fishes have developed gastric glands. The pepsin secreted by gastric glands is in full contact with the food in the stomach cavity, which is helpful for the digestion of animal protein in the acid environment of the cardia and blind sac. Therefore, the main function of the stomach is to digest the protein in the food. At the pylorus of the stomach, there is a tissue structure as the transition from the stomach to the intestine, and the gastric gland tissue is undeveloped or even just disappears, which indicates that the pylorus is the place that continuously digests the food mixed with digestive enzymes from the cardia and blind sac. The developed muscle layer in the stomach wall strengthens the peristalsis of the stomach, which is conducive to the full contact of food and digestive fluid. In addition, there are goblet cells in the stomach, which can not only play a lubrication function, but also prevent acid gastric juice from damaging the mucosa. 
There are many blood capillaries in the mucosa, and we can see that many blood cells are distributed in the lamina propria, which can rapidly transport nutrients. The loose connective tissue in the submucosa can buffer the extrusion of chyme and can give a good protection.

The surface structure and secretion ability of the intestinal mucosa are related to the digestive and absorptive capacity of the intestine ${ }^{[22,23]}$. The foregut of Sinogastromyzon szechuanensis receives food from the stomach cavity, and many wrinkles are formed in the mucosa, which prolongs the residence time of the food in the intestine; moreover, the height of the mucosa wrinkles in the foregut is the highest, increasing the contact area with the food and making the food be fully digested and absorbed. From the foregut to the hindgut, the density of goblet cells gradually increased, which is the same as that of most bony fishes ${ }^{[2-26]}$, indicating that the intestinal secretion ability gradually strengthens from the front to the back. Food is gradually digested and absorbed from the front to the back in the intestine. The increase of goblet cell density is convenient for the passage of food residues, fecal formation and fecal surface lubrication, which is conducive to defecation. At the same time, the trend of increasing of the wrinkles of the mucosa in the hindgut is conducive to increasing the contact area between the intestine and the chyme or food residue, and promoting the reabsorption of nutrients; in addition, the gradual thickening of the muscle layer from the foregut to the hindgut can also enhance the contractility and peristalsis ability of the intestine tract, and further promote the formation of feces and excretion of food residue. The significant differences in the structure of the foregut, the midgut and the hindgut indicate that there are differences in the digestion and absorption of nutrients in different segments of the intestine tract. Therefore, it can be inferred that the main part of the absorption of nutrients in Sinogastromyzon szechuanensis may be in the foregut.

There is a striated border structure on the free surface of the columnar epithelial cells in each segment of the intestine. On the one hand, the microvilli greatly increases the contact between food and intestinal tract, expands the effective area of digestion and absorption, and extends the retention time of food in intestinal tract to the greatest extent; on the other hand, the striated border structure is also related to the distribution of peptidase, disaccharidase and other digestive enzymes, which is conducive to the full digestion of food and the full absorption of nutrients; in addition, the microvilli can also retain the secretion of goblet cells, which has a buffering effect and can alleviate the mechanical damage of food on the intestinal wall ${ }^{[27-29]}$.

\section{Conclusion}

The morphology and tissue structure of the stomach and intestinal tract of Sinogastromyzon szechuanensis determine that each part of the stomach and intestines will perform different functions, showing a high degree of consistency with its omnivorous and partially-carnivorous characteristics. Therefore, we suggest that in the breeding process, animal-protein-based compound feed should be used. Due to the short digestive tract of this fish, we suggest that we should adopt a feeding method of "small feeding amount but multiple feeding times" when breeding Sinogastromyzon szechuanensis, which is good for its growth.

\section{Acknowledgments}

This research was financially supported by “Qing Lan Project of Jiangsu Province” (Teacher Jiangsu (2018) 12). It was also supported by "311 Talents Project in Taizhou" (2017Ш-804) and Jiangsu Agri-animal Husbandry Vocational College (Grant No. NSF201711).

Conflict of Interest: The authors declare that they have no conflict of interest.

Ethical approval: "All applicable international, national, and/or institutional guidelines for the care and use of animals were followed by the authors.” 


\section{References}

[1] XIONG F, LIU H Y, DUAN X B, et al. Present Status of Fishery Resources in Yinbin Section of the Upper Yangtze River, China[J]. Journal of Southwest University (Natural Science), 2015, 37(11): 43-50.

[2] YAO W Z. River Habitat Spawning and Restoration of Fishes_-Taking the Upper Reaches of the Yangtze River as an Example [C]. Proceedings of the 2nd International Conference on Modern Marine Pastures and the 2018 Annual Meeting of the Fisheries Resources and Environment Committee of the Chinese Fisheries Society Marine Ranch Professional Committee of Chinese Fisheries Society, Fisheries Resources and Environment Professional Committee of Chinese Fisheries Society: Marine Ranch Research Association of Chinese Fisheries Society, 2018: 100.

[3] JIANG $\mathrm{Y} \mathrm{H}, \mathrm{YAO} \mathrm{W} \mathrm{Z}$, WU Z L. Investigation on the status of fish resources in the Dagangshan reach of the Dadu River [C]. Proceedings of the 2nd Annual Conference of the Modern Marine Ranch International Symposium and the 2018 Annual Conference of the Fisheries Resources and Environment Committee of the Chinese Fisheries Society Marine Ranch Professional Committee of Chinese Fisheries Society, Fisheries Resources and Environment Professional Committee of Chinese Fisheries Society: Marine Ranch Research Association of Chinese Fisheries Society, 2018: 140.

[4] CHEN S H, OU Y J, LI J R, et al. Studies on morphology and histology of digestive tract in Liza haematocheila captived on the coast of Pearl River estuary, China[J]. Guangdong Agricultural Sciences, 2013, 17: 127-137.

[5] WANG Q Q. A study on fish resources of early life history stages in Chishui River and the early development of nine species of fish [D]. Central China Normal University, 2008.

[6] YANG Q R, CHEN Q W, MA X F. Status of Fish Resources and Protection Measures in the Lower Reaches of Yalong River, China[J]. Journal of Hydroecology, 2011, 32(3): 94-98.

[7] WU J M, WANG Q Q, LIU F, et al. Early Development of Sinogastromyzon szechuanensis in the Chishui River, China[J]. SICHUAN JOURNAL OF ZOOLOGY, 2011, 30(4): 527-529.

[8] WU J.M, LI L, Hao D U, et al. Length-weight relations of 14 endemic fish species from the upper Yangtze river basin, China[J]. Acta Ichthyol Piscat, 2013, 43(2): 163-165.

[9] LIU F, LI L, LIU H Z, et al. Diel drifting pattern of fish eggs in Chishui section of the Chishui River, China[J]. Freshwater Fisheries, 2014(06): 89-94.

[10] LIU K , WANG X D , WU B , et al. Length-weight relationships of 11 fish species from the Nuoshuihe precious water animal national nature reserve, southwestern China[J]. J Appl Ichthyol, 2017, 33(6): 1274-1276.

[11] Zou, Y C, Yan Y, Chen M, et al. Complete mitochondrial genome and phylogenetic analysis of Sinogastromyzon szechuanensis (Teleostei, Cypriniformes, Homalopteridae) [J]. Mitochondrial DNA B, 2018, 3(1): 272-273.

[12] WANG J, JIANG X M, PAN B Z, et al. Length-weight relationships of three indigenous fish species from national nature reserve for rare and endemic fishes of the upper Yangtze river, China[J]. J Appl Ichthyol, 2018, 34(4): 1014-1016.

[13] YUE L J, CHEN X J, LI W. Analysis and evaluation of nutritional components in muscle of Sinogastromyzon szechuanensis[J]. J Phys Conf Ser. 2019,1423(1): 012013.

[14] CHEN X J, XIONG L L, WU J G, et al. Effects of anesthetic eugenol on respiration and excretion of Sinogastromyzon szechuanensis[J]. J Phys Conf Ser. 2019,1423(1): 01004. 
[15] OU Y J, LIAO G Y, LI J E. Morphology and histology of the digestive tract in Cheilinus undulatus, China[J]. Journal of Tropical Oceanography, 2012, 31(6): 83-89.

[16] ZHANG J, WANG Y B, LI X M, et al. Histological observation on digestive system of Plectropomus leopardus under industrialized culture, China[J]. Marine Fisheries, 2015, 37(3): 233-243.

[17] OU Y J, LI J E, GOU X W, et al. Histological and histochemical study of digestive tract of Siganus oramin, China[J]. South China Fisheries Science, 2013, 9(5): 51-57.

[18] WANG Q, LIU M D, ZHU F Y, et al. Comparative Study of Three Species of Schizothoracine on Feeding and Digestive Organs in Upper Nujiang River, China[J]. Chinese Journal of Zoology, 2019, 54(2): 207-221.

[19] ZHANG L Z, YANG J H, ZHAO F, et al. Microstructure and ultrastructure observation of the digestive tract of Siganus canaliculatus, China[J]. JOURNAL OF FISHERIES OF CHINA, 2010, 34(2): 271-277.

[20] GOU X W, OU Y J, LIAO R. Histological and histochemical study of digestive system of Rhabdosargus sarba, China[J]. SOUTH CHINA FISHERIES SCIENCE, 2008, 4(5): 28-36.

[21] LIN S G, CHEN W L, ZHONG X R, et al. Microstructure and ultrastructure of digestive organ of Pseudosciaena crocea, China[J]. JOURNAL OF FISHERIES OF CHINA, 2002, 26(5): 396-401.

[22] HUANG F, WANG J, LUO J, et al. Microstructure and ultrastructure of the digestive tract of Gymnoth-orax reevesii, China[J]. Journal of Fishery Sciences of China, 2014, 33(6): 879-887.

[23] WANG Y C, LI J E, OU Y J, et al. Morphological and Histological Study on the Digestive Tract of Wild and Cultivated Yellowfin Black Porgy (Sparus latus), China[J]. Chinese Journal of Zoology, 2012, 47(3): 9-19.

[24] XIE B W, WANG Z J. Studies on Histology of Digestive System of Pelteobagrus Vachelli, China[J]. JOURNAL OF NEIJIANG TEACHERS COLLEGE, 2002, 17(2): 22-27.

[25] WU J Y, LIN H R. Histological studies on post-embryonic development of the digestive system of Epinephelus coioides, China[J]. JOURNAL OF FISHERIES OF CHINA, 2003, 27(2): 7-12.

[26] CHEN Y E, ZHENG X B, GAO X M, et al. Morphology, histology and digestive enzymes of the digestive tract of the amall yellow croaker larimichthys polyactis, China[J]. Oceanologia et Limnologia Sinica, 2019, 50(5): 1116-1126.

[27] Dai X, Shu M, Fang W. Histological and ultrastructural study of the digestive tract of rice field eel, Monopterus albus. Journal of Applied Ichthyology, 2007, 23(2): 177-183.

[28] Wilson J M, Castro L F C, 2010. Morphological diversity of the gastrointestinal tract in fishes. Fish Physiology, 30: 1-55.

[29] Nasruddin N S, Azmai M N A, Ismail A et al, 2014. Histological features of the gastrointestinal tract of wild Indonesian shortfin eel, Anguilla bicolor bicolor (McClelland, 1844), captured in Peninsular Malaysia. The Scientific World Journal, 2014: 312670. 